\title{
A real-world retrospective evaluation of glycaemic control and weight loss in patients with type 2 diabetes mellitus treated with canagliflozin $100 \mathrm{mg}$ and canagliflozin $300 \mathrm{mg}$ in an Indian setting
}

\section{ABSTRACT}

Background. Canagliflozin is a sodium glucose co-transporter 2 (SGLT2) inhibitor that improves glycaemia in patients with type 2 diabetes mellitus (T2DM) by enhancing urinary glucose excretion (UGE). Indian data regarding comparative efficacy of canagliflozin $300 \mathrm{mg}$ over canagliflozin $100 \mathrm{mg}$ in reduction of body weight are scanty.

Objectives. To evaluate and compare the efficacy of canagliflozin $100 \mathrm{mg}$ versus canagliflozin $300 \mathrm{mg}$ regarding loss of body weight retrospectively, in patients with T2DM inadequately controlled with other antihypergycaemic agents (AHA) in a real world setting in India.

Material and methods. T2DM patients inadequately controlled $\left(\mathrm{HbA}_{1 \mathrm{c}}>8.5 \%\right)$ with diet, exercise and AHA who were prescribed canagliflozin $100 \mathrm{mg}(n=62)$ or canagliflozin $300 \mathrm{mg}(\mathrm{n}=36)$ once daily, between May 2016 to May 2019 and were followed for at least 20 weeks, are included in the analysis. Changes in blood pressure and glycaemic parameters and body weight are studied.

Address for correspondence:

Dr. Poulomi Mukherjee

Lahabagan, Garia main road (Opposite H.P. pump)

Kolkata 700084

Phone: 9433955220

e-mail: poulomimukherjeegaria96@gmail.com

Clinical Diabetology 2020, 9; 5: 300-305

DOI: 10.5603/DK.2020.0031

Received: 10.04 .2020

Accepted: 03.08.2020
Results. Results show that addition of canagliflozin 100 and $300 \mathrm{mg}$ provided statistically significant improvements in glycaemic control associated with weight loss. However no superiority of canagliflozin $300 \mathrm{mg}$ to canagliflozin $100 \mathrm{mg}$ is established.

Conclusion. The present study shows that addition of canagliflozin $300 \mathrm{mg}$ has no advantage over canagliflozin $100 \mathrm{mg}$ on body weight when added on existing therapy with other AHA. (Clin Diabetol 2020; 9; 5: 300-305)

Key words: canagliflozin, SGLT2 inhibitors, T2DM

\section{Background}

The substantial increase in the incidence of type 2 diabetes mellitus (T2DM) over the past decade is associated with a marked increase in the prevalence of obesity, which contributes greatly to insulin resistance, a key pathophysiologic parameter observed especially in individuals at risk. Given the role of obesity and sedentary lifestyles in contributing to the progression of T2DM, the first step in T2DM management is lifestyle modification, exercise and weight loss [1]. With progressive deterioration in $\beta$-cell function ( $\beta C F)$ and mass, T2DM management progresses from non-pharmacological treatment to monotherapy (metformin being the preferred first line drug), to the need for combination drugs. Drugs that can provide glycaemic control independent of $\beta C F$ while having beneficial effects on weight are now preferred second line agent after metformin [2]. 
Canagliflozin is a sodium glucose co-transporter 2 (SGLT2) inhibitor developed for the treatment of patients with T2DM. SGLT2 found in the proximal renal tubule is a low affinity, high capacity transporter responsible for the majority $(90.0 \%)$ of renal glucose reabsorption [3,4]. Canagliflozin by inhibiting the SGLT2 co-transporter lowers the renal threshold for glucose $\left(\mathrm{RT}_{\mathrm{G}}\right.$ range $\left.4.4-5.0 \mathrm{mmol} / \mathrm{l}\right)$, thereby increasing urinary glucose excretion (UGE) and resulting in decreased plasma glucose, a mild osmotic diuresis and increased caloric loss (4 kcal/g of glucose), with a low potential for hypoglycaemia [5-9]. The loss of glucose with attendant caloric loss contributes to weight loss; in addition, improvements in $\beta C F$ have been seen $[5,8]$.

The recommended starting dose of canagliflozin is $100 \mathrm{mg}$ once daily, taken before the first meal of the day. Dose can be increased to $300 \mathrm{mg}$ once daily in patients tolerating canagliflozin $100 \mathrm{mg}$ once daily who have an eGFR of $60 \mathrm{~mL} / \mathrm{min} / 1.73 \mathrm{~m}^{2}$ or greater and require additional glycaemic control [10]. Several randomized controlled studies have found that canagliflozin $300 \mathrm{mg}$ is superior to sitagliptin and glimepiride as add-on therapy to metformin in achieving more effective glycaemic control [11-13].

The weight reducing effect of canagliflozin is an important therapeutic consideration for patients with T2DM who are overweight or obese. The incremental efficacy of canagliflozin $300 \mathrm{mg}$ on reducing postprandial plasma glucose peaks, is consistent with the hypothesis that it transiently inhibits intestinal SGLT1-mediated glucose absorption-the major intestinal glucose transporter, with perhaps a small contribution of delayed gastric emptying, possibly related to the increased glucagon-like peptide-1 (GLP-1) levels that assist in glycaemic and appetite control $[14,15]$. Interestingly, canagliflozin $300 \mathrm{mg}$ was found to significantly reduce body weight in obese and overweight patients without diabetes compared to placebo [16]. However there is paucity of real world data regarding superiority of canagliflozin $300 \mathrm{mg}$ over canagliflozin $100 \mathrm{mg}$ in reduction of body weight in Indian setting. This study compared the efficacy and weight loss benefit of two doses of canagliflozin (100 and $300 \mathrm{mg}$ ) as an add-on therapy in patients with T2DM inadequately controlled with other antihyperglycaemic agent (AHA).

\section{Materials and methods \\ Study design}

This retrospective, real-world observational study was conducted in a tertiary care setting in Kolkata to evaluate and compare the efficacy of two doses of canagliflozin 100 and $300 \mathrm{mg}$ regarding weight loss potential in T2DM patients who were inadequately controlled $\left(\mathrm{HbA}_{1 \mathrm{c}}>8.5 \%\right)$ with diet, exercise and other AHAs. The patients underwent minimum 20 weeks treatment from May 2016 to May 2019.

\section{Protocol characteristics}

Eligible patients were adult ( $\geq 18$ years) men and women with T2DM who had inadequate glycaemic control on diet, exercise and AHAs including oral antidiabetic drugs (OAD), non-insulin injectable agents and insulin injections at maximally or near-maximally effective doses. Patients not adequately controlled were defined as either having one or more of the following parameters: fasting glucose (FPG) $>150 \mathrm{mg} / \mathrm{dL}$, post prandial plasma glucose $(\mathrm{PPPG})>200 \mathrm{mg} / \mathrm{dL}, \mathrm{HbA}_{1 \mathrm{c}}$ $>8.5 \%$ despite receiving optimal dose of two or three antihypergycaemic agents [17]. Subjects were excluded if they had a history of type 1 diabetes, diabetic ketoacidosis, alcohol or drug dependence, recent or multiple hospitalization for reasons other than hyper glycaemia within past six months, nursing women, history of urinary tract or other systemic infections, haematuria, decompensated heart failure, liver failure, debilitating illness that may adversely affect renal function or on drugs that may adversely affect renal function. Total 98 patients who came to the study setting during the study period fitted the above mentioned criteria and were prescribed canagliflozin for a minimum period of 20 weeks. As weight change can also be affected by lifestyle therapy (diet and exercise), the subjects were advised at the beginning not to alter these and at subsequent visits the same was ensured. Comparability between the two groups of patients receiving canagliflozin 100 and $300 \mathrm{mg}$ was ensured. Decision on prescribing canagliflozin $100 \mathrm{mg}$ or $300 \mathrm{mg}$ was taken by examining physician based on patient's body weight.

\section{Data collection}

Baseline data of various parameters on the day of starting treatment with canagliflozin were collected from previous records. Data included all patients' demographic records with respect to age, gender, anthropometric measurements like height, weight, body mass index (BMI) and clinical parameters like systolic blood pressure (SBP), diastolic blood pressure (DBP). Laboratory investigations data included $\mathrm{HbA}_{1 \mathrm{C}^{\prime}}$ FPG, PPPG, serum creatinine $(\mathrm{Cr})$. Weight was recorded for each patient using an electronic weighing scale in the study setting following proper standardization procedure. BP was measured by mercury sphygmomanometer. Cuff size of $16 \times 30 \mathrm{~cm}$ was chosen while measuring BP for non-obese patients and larger cuff $(16 \times 36 \mathrm{~cm})$ was used for obese patients. Plasma glucose was measured by hexokinase method and 
$\mathrm{HbA}_{1 \mathrm{c}}$ was measured by high performance liquid chromatographic (HPLC) method (Bio-RAD D-10, Bio-RAD, and Hercules, CA, USA) in the institute. Data were collected from only those patients who completed at least 20 weeks of treatment period with canagliflozin $100 \mathrm{mg}$ or $300 \mathrm{mg}$.

Recordings of body weight, SBP, DBP, $\mathrm{HbA}_{1 c^{\prime}}$ FPG, PPPG, $\mathrm{Cr}$ in the study group at last follow-up were collected from records. The primary parameter was change in weight from baseline at last follow up. Other secondary parameters studied included change in $\mathrm{HbA}_{1 \mathrm{c}^{\prime}}$ FPG, PPPG and SBP from baseline at final follow up. To evaluate safety profile of canaglifozin adverse events due to genital mycotic infections were noted.

\section{Statistical analysis}

The data were analysed using SPSS statistics version 21. Comparability of both groups at baseline was assessed by independent t-test and nonparametric counterpart Mann-Whitney $U$ test. Before treatment and after treatment efficacy data of canagliflozin within groups were analysed by paired sample t-test. To compare the efficacy of canagliflozin $300 \mathrm{mg}$ with canagliflozin $100 \mathrm{mg}$ in regards to body weight and BMI, ANCOVA was done. P value less than 0.05 was considered as statistically significant.

\section{Results}

In the present study, total 62 patients received canagliflozin $100 \mathrm{mg}$ and were followed up a for a mean period of 25 weeks whereas 36 patients received canagliflozin $300 \mathrm{mg}$ and were followed up a for a mean period of 24 weeks; patients were advised to take canagliflozin once daily before the first meal of the day.

Table 1 shows the baseline characteristics of the study subjects in the two groups receiving canagliflozin $100 \mathrm{mg}$ and canagliflozin $300 \mathrm{mg}$. Baseline patient demographic and disease characteristics were similar across the two groups except body weight which was significantly higher in the canagliflozin $300 \mathrm{mg}$ treatment group (Mann-Whitney $\mathrm{U}$ test, $\mathrm{P}=0.0001$ ). Overall the mean age of the patient was 52.12 years, $53.1 \%$ were male. Mean body weight was $78.81 \mathrm{~kg}$ and mean BMI was $29.68 \mathrm{~kg} / \mathrm{m}^{2}$ with $45.9 \%$ patients classified as obese (according to WHO classification of obesity BMI $\geq$ $30 \mathrm{~kg} / \mathrm{m}^{2}$ ) [18]. Mean FPG and PPPG level were 164.82 $\mathrm{mg} / \mathrm{dL}$ and $214.18 \mathrm{mg} / \mathrm{dL}$ respectively. Baseline mean $\mathrm{HbA}_{1 \mathrm{c}}$ was $8.33 \%$.

Table 2 shows that both doses of canagliflozin significantly reduced bodyweight from baseline to final follow up $(P<0.001)$. Analysis of $\mathrm{BMI}$ also showed significant reduction in both canagliflozin groups ( $P$ value 0.001 and 0.002 respectively).
As the baseline body weight differed significantly in the two groups, ANCOVA was done for adjustment for the baseline body weight and BMI. After adjustment of baseline body weight and BMI estimated mean treatment differences between CANA 300 \& CANA 100 with $95 \%$ confidence interval were $1.41(-0.902$ to 1.878$)$ and 0.40 ( -0.112 to 0.922 ) respectively which were not statistically significant ( $P$ value 0.957 and 0.123 respectively).

Table 3 shows glycaemic efficacy of the two doses of canagliflozin. $\mathrm{HbA}_{1 \mathrm{c}}$ was significantly reduced from baseline with canagliflozin 100 and $300 \mathrm{mg}(\mathrm{P}<0.0001$ and 0.01 respectively). Subgroup analysis showed substantially greater reductions in $\mathrm{HbA}_{1 c}(P<0.01)$ with both canagliflozin doses in patients with higher $\left(\mathrm{HbA}_{1 \mathrm{c}}>9 \%\right)$, relative to those with lower, baseline $\mathrm{HbA}_{1 \mathrm{c}}$. Proportion of patients who achieved $\mathrm{HbA}_{1 \mathrm{c}}<$ $7.0 \%$ at final follow up with canagliflozin $100 \mathrm{mg}$ and $300 \mathrm{mg}$ were $31.1 \%$ and $27.8 \%$ respectively. Significant improvement from baseline in FPG was observed; $\mathrm{P}<$ 0.001 for both canagliflozin doses. PPPG reduction was also noted to be significant $(P \leq 0.001$ for both canagliflozin doses).

Reductions from baseline in SBP and DBP at week 25 seen with canagliflozin $100 \mathrm{mg}$ were statistically significant ( $P=0.024$ and 0.041 respectively). However reductions in SBP and DBP with canagliflozin $300 \mathrm{mg}$ were found to be statistically insignificant.

Over the time, both canagliflozin doses were associated with higher rates of adverse events consistent with genital mycotic infections in the study groups. Frequency of genital mycotic infection associated with canagliflozin $100 \mathrm{mg}$ and $300 \mathrm{mg}$ was $21 \%$ and $11.1 \%$ respectively and the difference was statistically nonsignificant (chi square, $\mathrm{P}>0.05$ ) (Table 4).

\section{Discussion}

In this study of subjects with T2DM who had inadequate glycaemic control with other AHA, treatment with canagliflozin 100 and $300 \mathrm{mg}$ provided statistically significant improvements in glycaemic control over 25 weeks and 24 weeks respectively; these improvements were associated with weight loss with both doses of canagliflozin.

Both treatment groups showed reductions in all glycaemic parameters - $\mathrm{HbA}_{1 \mathrm{c}^{\prime}} \mathrm{FPG}$, and PPPG. A large proportion of subjects reached $\mathrm{HbA}_{1 \mathrm{c}}<7.0 \%$ with canagliflozin. These results are consistent with reports from randomised controlled trials (RCT) conducted previously [13, 14, 19]. In the high glycaemic group $\left(\mathrm{HbA}_{1 \mathrm{c}}>9 \%\right)$, both canagliflozin doses substantially improved glycaemic parameters similar to results from previous study. Because UGE is proportional to the glucose concentration above $\mathrm{RT}_{\mathrm{G}}$, subjects with higher 
Table 1. Baseline demographic and disease characteristics of the overall study subjects $(n=98)$

\begin{tabular}{lccc}
\hline Study parameter & $\begin{array}{c}\text { CANA } \mathbf{1 0 0} \mathbf{~} \mathbf{g} \\
(\mathbf{n}=62)\end{array}$ & $\begin{array}{c}\text { CANA } \mathbf{3 0 0} \mathbf{~ m g} \\
(\mathbf{n}=\mathbf{3 6})\end{array}$ & $\begin{array}{c}\text { Total } \\
(\mathbf{n}=\mathbf{9 8})\end{array}$ \\
\hline Gender, $\mathrm{n}(\%)$ & & & $52(53.1)$ \\
$\quad$ Male & $35(56.45)$ & $17(47.22)$ & $46(46.9)$ \\
$\quad$ Female & $27(43.55)$ & $19(52.78)$ & $52.12 \pm 9.45$ \\
Age (years) & $52.68 \pm 8.79$ & $51.17 \pm 10.55$ & $78.81 \pm 13.78$ \\
Body weight $[\mathrm{kg}]$ & $74.06 \pm 10.62$ & $86.99 \pm 14.88$ & $29.68 \pm 4.72$ \\
BMI $\left[\mathrm{kg} / \mathrm{m}^{2}\right]$ & $28.16 \pm 3.92$ & $32.31 \pm 4.88$ & $130.78 \pm 13.38$ \\
SBP $[\mathrm{mm} \mathrm{Hg}]$ & $130.65 \pm 13.69$ & $131.00 \pm 13.02$ & $83.46 \pm 8.37$ \\
DBP $[\mathrm{mm} \mathrm{Hg}]$ & $83.40 \pm 8.38$ & $83.56 \pm 8.47$ & $8.33 \pm 1.50$ \\
HbA ${ }_{1 \mathrm{c}}(\%)$ & $8.45 \pm 1.65$ & $8.16 \pm 1.20$ & $164.82 \pm 50.02$ \\
FPG $[\mathrm{mg} / \mathrm{dL}]$ & $164.90 \pm 46.14$ & $164.68 \pm 56.78$ & $214.18 \pm 68.51$ \\
PPPG $[\mathrm{mg} / \mathrm{dL}]$ & $214.50 \pm 71.88$ & $213.64 \pm 63.27$ & $0.88 \pm 0.20$ \\
Serum Cr $[\mathrm{mg} / \mathrm{dL}]$ & $0.89 \pm 0.20$ & $0.87 \pm 0.20$ & $45(45.9)$ \\
Obesity, $\mathrm{n}(\%)$ & $18(29.0)$ & $27(75.0)$ & \\
\hline
\end{tabular}

Table 2. Changes from baseline in bodyweight and BMI at final follow up*

\begin{tabular}{|c|c|c|c|c|c|c|c|c|}
\hline \multirow{2}{*}{$\begin{array}{l}\text { Canagliflozin } \\
\text { doses }\end{array}$} & \multicolumn{2}{|c|}{ Baseline } & \multicolumn{2}{|c|}{ Final follow up } & \multirow{2}{*}{$\begin{array}{c}\text { Mean } \\
\text { differences }\end{array}$} & \multirow[t]{2}{*}{$\mathbf{t}$} & \multirow{2}{*}{$\begin{array}{l}\text { P value diff. } \\
\text { within the } \\
\text { groups }\end{array}$} & \multirow{2}{*}{$\begin{array}{c}\text { P value diff. } \\
\text { between the } \\
\text { groups }\end{array}$} \\
\hline & Mean & SD & Mean & SD & & & & \\
\hline \multicolumn{9}{|c|}{ Body weight changes [kg] } \\
\hline CANA $100 \mathrm{mg}(\mathrm{n}=62)$ & 74.06 & 10.62 & 72.69 & 10.26 & 1.37 & 4.063 & $<0.001$ & 0.957 \\
\hline CANA $300 \mathrm{mg}(\mathrm{n}=36)$ & 86.99 & 14.88 & 85.08 & 14.58 & 1.91 & 3.839 & $<0.001$ & \\
\hline \multicolumn{9}{|l|}{ BMI changes $\left[\mathrm{kg} / \mathrm{m}^{2}\right]$} \\
\hline CANA $100 \mathrm{mg}(\mathrm{n}=62)$ & 28.16 & 3.92 & 27.62 & 3.79 & 0.54 & 3.646 & 0.001 & 0.123 \\
\hline CANA $300 \mathrm{mg}(\mathrm{n}=36)$ & 32.31 & 4.88 & 31.72 & 4.58 & 0.59 & 3.444 & 0.002 & \\
\hline
\end{tabular}

*Canagliflozin $100 \mathrm{mg}-25$ weeks, canagliflozin $300 \mathrm{mg}-24$ weeks. $\mathrm{P}<0.05$ considered as statistically significant, $\mathrm{p}$ value within the groups computed by paired sample t-test, $\mathrm{P}$ value between the groups computed by ANCOVA

Table 3. Summary of changes from baseline in glycaemic parameters and blood pressure at final follow up*

\begin{tabular}{|c|c|c|c|c|c|c|c|}
\hline \multirow[t]{2}{*}{ Canagliflozin doses } & \multicolumn{2}{|c|}{ Baseline } & \multicolumn{2}{|c|}{ Final follow up } & \multirow{2}{*}{$\begin{array}{c}\text { Mean } \\
\text { differences }\end{array}$} & \multirow[t]{2}{*}{$\mathbf{t}$} & \multirow[t]{2}{*}{$\mathbf{p}$} \\
\hline & Mean & SD & Mean & SD & & & \\
\hline \multicolumn{8}{|l|}{ FPG [mg/dL] } \\
\hline CANA $100 \mathrm{mg}(\mathrm{n}=62)$ & 164.90 & 46.14 & 138.49 & 42.78 & 26.41 & 3.706 & $<0.001$ \\
\hline CANA $300 \mathrm{mg}(\mathrm{n}=36)$ & 164.68 & 56.78 & 128.36 & 25.63 & 36.32 & 4.113 & $<0.001$ \\
\hline \multicolumn{8}{|l|}{ PPPG [mg/dL] } \\
\hline CANA $100 \mathrm{mg}(\mathrm{n}=62)$ & 212.39 & 70.53 & 176.22 & 52.31 & 36.17 & 4.033 & $<0.001$ \\
\hline CANA $300 \mathrm{mg}(\mathrm{n}=36)$ & 213.64 & 63.27 & 173.39 & 42.24 & 40.25 & 3.581 & 0.001 \\
\hline \multicolumn{8}{|l|}{$\mathrm{HBA}_{1 \mathrm{c}}[\%]$} \\
\hline CANA $100 \mathrm{mg}(\mathrm{n}=62)$ & 8.435 & 1.6619 & 7.655 & 1.3143 & 0.78 & 4.834 & $<0.0001$ \\
\hline CANA $300 \mathrm{mg}(\mathrm{n}=36)$ & 8.115 & 1.2032 & 7.543 & 1.0058 & 0.572 & 2.581 & 0.014 \\
\hline \multicolumn{8}{|l|}{ SBP $[\mathrm{mm} \mathrm{Hg}]$} \\
\hline CANA $100 \mathrm{mg}(\mathrm{n}=62)$ & 130.65 & 13.69 & 127.92 & 11.19 & 2.73 & 2.261 & 0.024 \\
\hline CANA $300 \mathrm{mg}(\mathrm{n}=36)$ & 131.00 & 13.02 & 128.03 & 10.61 & 2.97 & 1.525 & 0.136 \\
\hline \multicolumn{8}{|l|}{ DBP $[\mathrm{mm} \mathrm{Hg}]$} \\
\hline CANA $100 \mathrm{mg}(\mathrm{n}=62)$ & 83.40 & 8.38 & 81.27 & 7.04 & 2.13 & 2.088 & 0.041 \\
\hline CANA $300 \mathrm{mg}(\mathrm{n}=36)$ & 83.56 & 8.47 & 81.42 & 7.87 & 2.14 & 1.423 & 0.164 \\
\hline
\end{tabular}

*Canagliflozin $100 \mathrm{mg}-25$ weeks, canagliflozin $300 \mathrm{mg}-24$ weeks. $\mathrm{P}<0.05$ considered as statistically significant, $\mathrm{p}$ computed by paired sample T-test 
Table 4. Frequency of genital mycotic infection of canagliflozin 100 and $300 \mathrm{mg}$ over the treatment period*

\begin{tabular}{lcc}
\hline Adverse effect & $\begin{array}{c}\text { CANA 100 } \mathbf{~ m g} \\
(\mathbf{n}=62)\end{array}$ & $\begin{array}{c}\text { CANA 300 } \mathbf{~ m g} \\
(\mathbf{n}=36)\end{array}$ \\
\hline $\begin{array}{l}\text { Genital mycotic } \\
\text { infection [n (\%)] }\end{array}$ & $13(20.97 \%)$ & $4(11.1 \%)$ \\
\hline
\end{tabular}

${ }^{*}$ Canagliflozin $100 \mathrm{mg}-25$ weeks, canagliflozin $300 \mathrm{mg}-24$ weeks

baseline glucose level might be expected to show greater UGE and osmotic diuresis resulting in greater glycaemic efficacy of canagliflozin [14].

Addressing obesity is an important part of T2DM management. Because many of the traditional therapies for T2DM result in weight gain, the added benefit of weight loss with canagliflozin is clinically useful [20]. In the present study canagliflozin 100 and $300 \mathrm{mg}$ both showed significant body weight reduction from baseline similar to findings noted with other studies $[13,14,19]$. While body composition measurements were not performed in this study, analyses conducted in other phase 3 studies in patients with T2DM showed that approximately two-thirds of the reduction in body mass seen with canagliflozin was from fat mass and one-third was from lean body mass [13]. In clinical studies of weight loss, modest reductions in body weight have been associated with favourable improvements in cardiovascular risk factors, including lipids, BP, and inflammatory markers [21].

In the present study canagliflozin $100 \mathrm{mg}$ was associated with a statistically significant reduction in SBP and DBP from baseline; however no such association was found in case of canagliflozin $300 \mathrm{mg}$ though BP reduction was similar in both groups (mean differences in SBP $-2.73 \mathrm{~mm} \mathrm{Hg}$ in canagliflozin $100 \mathrm{mg},-2.97 \mathrm{~mm} \mathrm{Hg}$ in canagliflozin $300 \mathrm{mg}$ group and mean differences in DBP $-2.13 \mathrm{~mm} \mathrm{Hg}$ in canagliflozin $100 \mathrm{mg},-2.14 \mathrm{~mm} \mathrm{Hg}$ in canagliflozin $300 \mathrm{mg}$ group). This is in contrary to the previous studies which reported favourable improvements in SBP with both doses of canagliflozin [14]. The above finding can be due to smaller sample size in canagliflozin $300 \mathrm{mg}$ group.

Relative to canagliflozin $100 \mathrm{mg}$ an incremental efficacy on glycaemic endpoints, body weight and systolic BP of canagliflozin $300 \mathrm{mg}$ was observed in a randomised controlled trial (RCT) conducted previously [14]. Clinical mechanism of action studies [15, 22] have confirmed delayed gastrointestinal glucose absorption with canagliflozin $300 \mathrm{mg}$ in healthy volunteers and subjects with T2DM. However in the present study, despite absolute weight reduction was higher in the canagliflozin $300 \mathrm{mg}$ group (mean differences 1.91 vs. $1.37 \mathrm{~kg}$ ), this difference appeared to be insignificant. No significant difference was also found between the two doses of canagliflozin in respect to change of BMI although in this case difference was smaller (mean differences 0.59 vs. $0.54 \mathrm{~kg} / \mathrm{m}^{2}$ ). This lack of significance can probably be attributed to small study groups.

The observed frequencies of genital mycotic infection in this study in both canagliflozin groups were higher than in previous RCTs; these were generally mild or moderate in severity and treated by antifungal therapies $[8,19,23,24]$.

Finally the limitations of this study must be considered. One limitation of the study is small number of participants which may explain a lack of significance of some of the findings. Besides this is a real world study (RWS) and propensity score matching of the confounding factors between the two groups were not done due to limited sample size. Randomisation and placebo controlling was not possible in RWS. In addition, the treatment period under observation was short; a longer duration of observation with a larger sample size is needed to understand the comparative benefits and risks of these drugs and the durability of response. Finally, we did not assess the other potential adverse effects of canagliflozin like hypoglycaemia, postural dizziness and changes in eGFR. These issues might have implication in the result and outcome of the study.

\section{Conclusion}

The present study showed that canagliflozin 100 and $300 \mathrm{mg}$ significantly improved glycaemic control, reduced body weight in subjects with T2DM inadequately controlled with diet, exercise and other AHA. Canagliflozin $100 \mathrm{mg}$ additionally caused reduction in SBP and DBP. This the only Indian real world study is thus consistent with RCTs and real world studies of western world. However no superiority of canagliflozin $300 \mathrm{mg}$ to canagliflozin $100 \mathrm{mg}$ in respect to body weight was established in this study.

\section{Conflict of interest}

The authors report no conflicts of interest in this study.

\section{REFERENCES}

1. Prasanna Kumar KM, Ghosh S, Canovatchel W, et al. A review of clinical efficacy and safety of canagliflozin $300 \mathrm{mg}$ in the management of patients with type 2 diabetes mellitus. Indian J Endocrinol Metab. 2017; 21(1): 196-209, doi: 10.4103/2230-8210.196016, indexed in Pubmed: 28217522.

2. Davies MJ, D'Alessio DA, Fradkin J, et al. Management of Hyperglycemia in Type 2 Diabetes, 2018. A Consensus Report by the American Diabetes Association (ADA) and the European Association for the Study of Diabetes (EASD). Diabetes Care. 2018; 41(12): 2669-2701, doi: 10.2337/dci18-0033, indexed in Pubmed: 30291106. 
3. Nauck MA. Update on developments with SGLT2 inhibitors in the management of type 2 diabetes. Drug Des Devel Ther. 2014; 8: 1335-1380, doi: 10.2147/DDDT.S50773, indexed in Pubmed: 25246775.

4. Wright EM, Loo DDF, Hirayama BA. Biology of human sodium glucose transporters. Physiol Rev. 2011; 91(2): 733-794, doi: 10.1152/physrev.00055.2009, indexed in Pubmed: 21527736.

5. Devineni $D$, Morrow $L$, Hompesch $M$, et al. Canagliflozin improves glycaemic control over 28 days in subjects with type 2 diabetes not optimally controlled on insulin. Diabetes Obes Metab. 2012; 14(6): 539-545, doi: 10.1111/j.1463-1326.2012.01558.x, indexed in Pubmed: 22226086.

6. Liang Y, Arakawa K, Ueta K, et al. Effect of canagliflozin on renal threshold for glucose, glycemia, and body weight in normal and diabetic animal models. PLoS One. 2012; 7(2): e30555, doi: 10.1371/journal.pone.0030555, indexed in Pubmed: 22355316.

7. Nomura S, Sakamaki S, Hongu M, et al. Discovery of canagliflozin, a novel C-glucoside with thiophene ring, as sodium-dependent glucose cotransporter 2 inhibitor for the treatment of type 2 diabetes mellitus. J Med Chem. 2010; 53(17): 6355-6360, doi: 10.1021/jm100332n, indexed in Pubmed: 20690635.

8. Rosenstock J, Aggarwal N, Polidori D, et al. Canagliflozin DIA 2001 Study Group. Dose-ranging effects of canagliflozin, a sodium-glucose cotransporter 2 inhibitor, as add-on to metformin in subjects with type 2 diabetes. Diabetes Care. 2012; 35(6): 1232-1238, doi: 10.2337/dc11-1926, indexed in Pubmed: 22492586.

9. Sha S, Devineni D, Ghosh A, et al. Canagliflozin, a novel inhibitor of sodium glucose co-transporter 2 , dose dependently reduces calculated renal threshold for glucose excretion and increases urinary glucose excretion in healthy subjects. Diabetes Obes Metab. 2011; 13(7): 669-672, doi: 10.1111/j.1463-1326.2011.01406.x, indexed in Pubmed: 21457428.

10. INVOKANA ${ }^{\circledR}$ (Canagliflozin) Tablets. Highlights of Prescribing Information; 2016. Available from: https://www.accessdata. fda.gov/drugsatfda_docs/label/2018/204042s027lbl.pdf [Last accessed on September 22 2019].

11. Lavalle-González FJ, Januszewicz A, Davidson J, et al. Efficacy and safety of canagliflozin compared with placebo and sitagliptin in patients with type 2 diabetes on background metformin monotherapy: a randomised trial. Diabetologia. 2013; 56(12): 2582-2592, doi: 10.1007/s00125-013-3039-1, indexed in Pubmed: 24026211.

12. Schernthaner G, Gross JL, Rosenstock J, et al. Canagliflozin compared with sitagliptin for patients with type 2 diabetes who do not have adequate glycemic control with metformin plus sulfonylurea: a 52-week randomized trial. Diabetes Care. 2013; 36(9): 2508-2515, doi: 10.2337/dc12-2491, indexed in Pubmed: 23564919.

13. Cefalu W, Leiter L, Yoon $\mathrm{KH}$, et al. Efficacy and safety of canagliflozin versus glimepiride in patients with type 2 diabetes inadequately controlled with metformin (CANTATA-SU): 52 week results from a randomised, double-blind, phase 3 non-inferiority trial. Lancet. 2013; 382(9896): 941-950, doi: 10.1016/s01406736(13)60683-2.

14. Stenlöf K, Cefalu WT, Kim KA, et al. Efficacy and safety of canagliflozin monotherapy in subjects with type 2 diabetes mellitus inadequately controlled with diet and exercise. Diabetes Obes Metab. 2013; 15(4): 372-382, doi: 10.1111/dom.12054, indexed in Pubmed: 23279307.

15. Polidori D, Sha S, Mudaliar S, et al. Canagliflozin lowers postprandial glucose and insulin by delaying intestinal glucose absorption in addition to increasing urinary glucose excretion: results of a randomized, placebo-controlled study. Diabetes Care. 2013; 36(8): 2154-2161, doi: 10.2337/dc12-2391, indexed in Pubmed: 23412078.

16. Bays HE, Weinstein R, Law G, et al. Canagliflozin: effects in overweight and obese subjects without diabetes mellitus. Obesity (Silver Spring). 2014; 22(4): 1042-1049, doi: 10.1002/oby.20663, indexed in Pubmed: 24227660.

17. Das, A K and Sahay, B K and Seshiah et al. Indian National Consensus Group: National Guidelines on Initiation and Intensification of Insulin Therapy with Premixed Insulin Analogs. Available from: http://mdrf-eprints.in/868/[Last accessed on September 22 2019].

18. World Health Organization.Body mass index - BMI. Available from: http://www.euro.who.int/en/health-topics/disease-prevention/nutrition/a-healthy-lifestyle/body-mass-index-bm [Last accessed on September 22 2019].

19. Wilding JPH, Charpentier G, Hollander P, et al. Efficacy and safety of canagliflozin in patients with type 2 diabetes mellitus inadequately controlled with metformin and sulphonylurea: a randomised trial. Int J Clin Pract. 2013; 67(12): 1267-1282, doi: 10.1111/ijcp.12322, indexed in Pubmed: 24118688.

20. Diabetes Prevention Program Research Group. Long-term safety, tolerability, and weight loss associated with metformin in the Diabetes Prevention Program Outcomes Study. Diabetes Care. 2012; 35(4): 731-737, doi: 10.2337/dc11-1299, indexed in Pubmed: 22442396.

21. Klein S, Burke LE, Bray GA, et al. American Heart Association Council on Nutrition, Physical Activity, and Metabolism. Clinical implications of obesity with specific focus on cardiovascular disease: a statement for professionals from the American Heart Association Council on Nutrition, Physical Activity, and Metabolism: endorsed by the American College of Cardiology Foundation. Circulation. 2004; 110(18): 2952-2967, doi: 10.1161/01. CIR.0000145546.97738.1E, indexed in Pubmed: 15509809.

22. Stein P, Berg JK, Morrow L, et al. Canagliflozin, a sodium glucose co-transporter 2 inhibitor, reduces post-meal glucose excursion in patients with type 2 diabetes by a non-renal mechanism: results of a randomized trial. Metabolism. 2014; 63(10): 1296-1303, doi: 10.1016/j.metabol.2014.07.003, indexed in Pubmed: 25110280.

23. Nicolle LE, Capuano G, Ways K, et al. Effect of canagliflozin, a sodium glucose co-transporter 2 (SGLT2) inhibitor, on bacteriuria and urinary tract infection in subjects with type 2 diabetes enrolled in a 12-week, phase 2 study. Curr Med Res Opin. 2012; 28(7): 1167-1171, doi: 10.1185/03007995.2012.689956, indexed in Pubmed: 22548646.

24. Nyirjesy P, Zhao Y, Ways K, et al. Evaluation of vulvovaginal symptoms and Candida colonization in women with type 2 diabetes mellitus treated with canagliflozin, a sodium glucose co-transporter 2 inhibitor. Curr Med Res Opin. 2012; 28(7): 1173-1178, doi: 10.1185/03007995.2012.697053, indexed in Pubmed: 22632452. 